\title{
Preparation of stimulus-sensitive gel particles with a DNA-dye complex and their $\mathrm{pH}$ sensitivity
}

\author{
Takashi Nishiyama $^{1}$, Yoshiharu Kagami ${ }^{2}$, Takeshi Yamauchi ${ }^{1,3}$ and Norio Tsubokawa ${ }^{1,3}$ \\ In this study, stimulus-sensitive gel particles with DNA-dye complexes were prepared. This composite has potential use in \\ optical micro-sensors because it can change its dye concentration in response to stimuli by intercalating dye into DNA. \\ Poly(acrylic acid) (PAAC) gel particles containing DNA were synthesized by emulsion polymerization and immersed in ethidium \\ bromide (EtBr) solution to form DNA-EtBr complexes by intercalating dyes in the double-stranded structure. The $\mathrm{pH}$ response \\ characteristics were measured in buffer solution with an optical and fluorescence microscope, and the dye entrapment of the \\ composite was evaluated with a UV-Visible spectrophotometer. As a result, the EtBr was immobilized in PAAc gel particles \\ containing DNA, and its volume could be varied by changing the $\mathrm{pH}$ in buffer solution. Furthermore, by forming the gel in a \\ particle shape, the PAAc gel reached equilibrium swelling in about $60 \mathrm{~s}$. The fluorescence intensity of PAAc gel particles \\ embedded with DNA-EtBr complexes displayed high-sensitivity and was found to exponentially decrease as a function of $\mathrm{pH}$. \\ Polymer Journal (2012) 44, 396-400; doi:10.1038/pj.2011.142; published online 25 January 2012
}

Keywords: DNA; fluorescence property; pH sensitivity; stimulus-sensitive gel particle

\section{INTRODUCTION}

Stimulus-sensitive gels change their volume in response to environmental stimuli such as $\mathrm{pH}$, temperature, light, electric field and biomolecules. $^{1-5}$ These soft and smart materials are expected to be developed for use in sensor devices in various fields. ${ }^{6-7}$ However, it is necessary to improve the stimulus response speed of stimulus-sensitive gels for application in novel sensor devices. It is well known that the stimulus response speed of various polymer gels is dependent on the volume. For sensor applications, the improvement of stimulus response speed is one of the important challenges. Gel micro-particles have a low volume and a high-specific surface area. ${ }^{8}$ These properties make it possible to improve the stimulus response speed using a stimulus-sensitive gel formed into micro- or nano-particles.

Stimulus-sensitive gels containing dye are applied to optical sensor devices to detect fluorescence intensity resulting from volume changes in response to environmental stimuli. However, most of the dye in the gels is eluted to an external solution through threedimensional polymer networks, which is an approach that is fundamentally limited in achieving faster sensor response times. Consequently, we focused on dye entrapment of DNA into stimulussensitive gels to develop a new type of optical sensor device. It has been previously reported that certain kinds of dye can be intercalated in double-stranded structure of DNA. ${ }^{9-14}$ Intercalated dye is immobilized in the double-stranded structure of DNA, and dye is not diffused to regions external to the DNA. Additionally, intercalated dye increased the fluorescence intensity because of inhibited concentration quenching and vibrational deactivation. Such characteristics of DNA would be useful for applications in optical devices. ${ }^{15-17}$ The optical sensing mechanism of composites containing stimulus-sensitive gels and a DNA-dye complex is that the volume of the composite will change in response to external stimuli. The volume alteration of the gel particles causes a change in the concentration of the dye because the dye is intercalated into DNA that is immobilized in the gel particles. When the concentration of the dye is varied by altering the volume of the gel particles, the amount of dye that is excited by laser illumination is changed. Therefore, the resulting fluorescence intensity of the gel particles is increased or decreased in response to external stimuli.

In this study, we investigated the preparation of PAAc gel particles with DNA-dye complexes and their $\mathrm{pH}$ response characteristics. PAAc gel is a soft material that can swell or contract in response to variations in $\mathrm{pH}$. Thus, PAAc gel particles with DNA-dye complexes could be used to detect local $\mathrm{pH}$ information in micro-regions as a photo signal. This unique characteristic is expected to be applied in optical micro-pH sensors in fields such as microbiology, cell studies and tissue engineering.

\section{EXPERIMENTAL PROCEDURE}

Materials and reagents

The monomer, acrylic acid (AAc) was purchased from Kanto Chemical Co., Inc. (Tokyo, Japan). AAc was purified by reduced-pressure distillation. $N, N^{\prime}$ methylene-bis-acrylamide, which was used as a crosslinking agent, was pur-

${ }^{1}$ Graduate School of Science and Technology, Niigata University, Niigata, Japan; ${ }^{2}$ kkuno Seisakusho Co., Ltd., Kawasaki, Kanagawa, Japan and ${ }^{3}$ Faculty of Engineering, Niigata University, Niigata, Japan

Correspondence: Professor T Yamauchi, Graduate School of Science and Technology, Niigata University, 8050, Ikarashi 2-nocho, Nishi-ku, Niigata 950-2181, Japan. E-mail: yamauchi@gs.niigata-u.ac.jp

Received 19 July 2011; revised 7 October 2011; accepted 13 November 2011; published online 25 January 2012 
chased from Wako Pure Chemical Industries, Ltd (Osaka, Japan). The initiator, potassium persulfate was purchased from Kanto Chemical Co., Inc. $N, N^{\prime}-$ methylene-bis-acrylamide and potassium persulfate were used without further purification. DNA was supplied by Ogata Material Science Institute Corp. (Hokkaido, Japan) Span 80, which was used as a surfactant, and cyclohexane were purchased from Kanto Chemical Co., Inc. EtBr, which was used as a fluorescent dye, was purchased from Wako Pure Chemical Industries, Ltd.

\section{Preparation of PAAc gel particles with the DNA-EtBr complex}

PAAc gel particles with DNA were prepared by emulsion polymerization. In this process, $0.721 \mathrm{~g}$ of AAc (the molarity of AAc was adjusted to $1 \mathrm{moll}^{-1}$ ) and $0.031 \mathrm{~g}$ of $N, N^{\prime}$-methylene-bis-acrylamide ( $2 \mathrm{~mol} \%$ relative to AAc) were first dissolved in distilled water. Subsequently, DNA (the molarity of the DNA was adjusted to $1 \mathrm{mmoll}^{-1}$ ) was dissolved in distilled water, and each solution was mixed thoroughly. This solution was dropped into $300 \mathrm{ml}$ of cyclohexane, while simultaneously adding $2.1 \mathrm{~g}$ of Span 80 , which is higher than the critical micelle concentration, and the resulting mixuture was stirred at 300 r.p.m. under a nitrogen atmosphere. Then, $0.054 \mathrm{~g}$ of potassium persulfate, which was deoxidized for $30 \mathrm{~min}$, was added, and the polymerization was performed at $60{ }^{\circ} \mathrm{C}$ for $6 \mathrm{~h}$. The obtained PAAc gel particles with DNA were micro-filtered and washed repeatedly in methanol with centrifugation $\left(15000\right.$ r.p.m., $10^{\circ} \mathrm{C}$, $30 \mathrm{~min})$. The PAAc gel particles with DNA were finally immersed in distilled water for $24 \mathrm{~h}$ to remove the unreacted reagents.

$\mathrm{EtBr}$ was used as a fluorescent dye. A suitable amount of $\mathrm{EtBr}$ was dissolved in distilled water. PAAc gel particles with DNA-EtBr complexes were prepared by immersing the PAAc gel particles containing the DNA into the EtBr solution. The PAAc gel particles with DNA-EtBr complexes were then immersed in distilled water until equilibrium swelling was reached.

\section{Evaluation of immobilized DNA in PAAc gel particles}

Confirmation of immobilized DNA within the PAAc gel particles was performed using a UV-Visible (UV-Vis) spectrophotometer (Shimadzu UV-1600, Shimadzu Corporation, Kyoto, Japan). The PAAc gel particles embedded with DNA were kept immersed in distilled water until equilibrium swelling was reached, and then they were measured over the UV-Vis spectra. The distilled water, in which the PAAc gel particles embedded with DNA were immersed, was also measured using UV-Vis spectra to evaluate the elution of DNA from the PAAc gel particles.

\section{Elution test of EtBr from PAAc gel particles with DNA}

The PAAc gel particles containing the DNA-EtBr complex were immersed for $24 \mathrm{~h}$ in distilled water and Tris (hydroxymethyl amino methane) hydrochloric acid (Tris-HCl) buffer solution, which was prepared at a concentration of $0.1 \mathrm{moll}^{-1}$ and $\mathrm{pH}$ of 7.4. PAAc gel particles containing DNA in Tris- $\mathrm{HCl}$ buffer solution were separated from the solution. The solution was then measured by a UV-Vis spectrophotometer to evaluate the elution of EtBr from gel particles containing DNA. PAAc gel particles without DNA were similarly measured.

pH-sensitivity of PAAc gel particles with the DNA-EtBr complex The evaluation of $\mathrm{pH}$ response speed was performed using a $0.1 \mathrm{moll}^{-1}$ of Tris$\mathrm{HCl}$ buffer solution, at a $\mathrm{pH}$ of 7.4. The PAAc gel particles containing the DNA-EtBr complex were immersed in the buffer solution, and then were examined by optical microscope (Shimadzu STZ-168-TL). The time response of the swelling ratio was measured with the image analysis system of the optical microscope.

The measurement of the swelling ratio of PAAc gel particles with DNA-EtBr complexes was performed using the image analysis system of the optical microscope, with several types of buffer solutions ( $\mathrm{pH} 2 \sim 12)$. The gel particles were kept immersed in distilled water until equilibrium swelling was reached. The distilled water was then removed, and the gel particles were immersed in each buffer solution for $10 \mathrm{~min}$. The volume of the PAAc gel particles with DNA-EtBr complexes was measured using the image analysis system of the optical microscope. The swelling ratio of PAAc gel particles with DNA-EtBr complexes was calculated by evaluating the volumes of the particles before and after immersion in each of the buffer solutions.

\section{Fluorescence property of PAAc gel particles with the DNA-EtBr} complex

The observation of fluorescence from PAAc gel particles with DNA-EtBr complexes was performed with a fluorescence microscope (Olympus, BX-51). The objective lenses used were as follows: UPlanI $10 \times(\mathrm{NA}=0.30$, $\mathrm{WD}=9.5 \mathrm{~mm})$, SLCPlanFI $40 \times(\mathrm{NA}=0.55, \mathrm{WD}=2.6 \mathrm{~mm})$ and UMPlanFI $50 \times(\mathrm{NA}=0.80, \mathrm{WD}=2.1 \mathrm{~mm})$.

The fluorescence intensity of PAAc gel particles with DNA-EtBr complexes was measured with a microspectrophotometer, which consists of a microscope, laser, ND filter, detector and monitor. The PAAc gel particles containing DNA$\mathrm{EtBr}$ complexes were kept immersed in distilled water until equilibrium swelling was reached. After the distilled water was removed, the PAAc gel particles with DNA-EtBr complexes were kept immersed in each of the buffer solutions for $5 \mathrm{~min}$. The fluorescence intensity of the gel particles was measured in the buffer solutions.

\section{RESULTS AND DISCUSSION}

Preparation of PAAc gel particles with the DNA-EtBr complex PAAc gel particles with DNA could be synthesized by emulsion polymerization as shown in Figure 1. The average diameter of the gel particles was about $250 \mu \mathrm{m}$, calculated from 100 measurements using the image analysis system of the optical microscope (Table 1). The critical micelle concentration of the surfactant, Span 80 was defined as the concentration at which surface-active agents form micelles. Therefore, PAAc gel particles with DNA were synthesized at surfactant concentrations higher than the critical micelle concentration.

\section{Evaluation of immobilized DNA into PAAc gel particles}

Figure 2 shows the UV-Vis spectrum of PAAc gel particles with DNA synthesized by emulsion polymerization. The signal from DNA is observed at the absorption peak from the nucleobases (adenine, guanine, cytosine and thymine) at $260 \mathrm{~nm}$. The absorption peak of PAAc gel particles with DNA was also observed at $260 \mathrm{~nm}$. The results indicated that DNA was included in the PAAc gel particles by this synthesis method. The amount of the DNA incorporated in the gel particles was measured by UV-Vis spectra. Using this synthesis process, the content of DNA in the gel particles was found to be $0.11 \mathrm{mmolg}^{-1}$. A small amount of DNA was incorporated due to swelling of the gel particles while washing and immersing in distilled water. The solution in which the PAAc gel particles with DNA were immersed for $24 \mathrm{~h}$ was not observed for the absorption peak from DNA at $260 \mathrm{~nm}$. DNA was not eluted from the PAAc gel particles
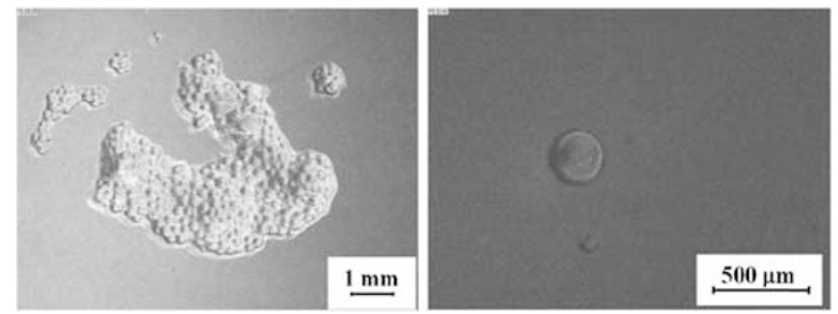

Figure 1 Optical micrographs of PAAc gel particles with DNA.

Table 1 Properties of PAAc gel particles with DNA

\begin{tabular}{lccc}
\hline & Average diameter $(\mu \mathrm{m})$ & s.d. $(\mu \mathrm{m})$ & $(\mathrm{CV})(\%)$ \\
\hline PAAc gel particle with DNA & 222.5 & 40.4 & 18.7 \\
\hline Abbreviations: CV, coefficient of variation; PAAc, Poly(acrylic acid). & &
\end{tabular}


because DNA entangles in the three-dimentional network structure of the gel particles.

\section{Elution of EtBr from PAAc gel particles containing DNA}

The PAAc gel particles containing the DNA-EtBr complexes were prepared by immersing PAAc gel particles with DNA in an EtBr solution. After $1 \mathrm{~h}$ of immersion in the solution, EtBr was incorporated in the PAAc gel particles with DNA. EtBr has an absorption peak at $490 \mathrm{~nm}$. The PAAc gel particles with DNA-EtBr complexes were evaluated to measure the elution of $\mathrm{EtBr}$ from the gel particles to external solution by using a UV-Vis spectrophotometer, as shown in Figure 3. In the case of the PAAc gel particles without DNA, the absorption peak of EtBr in the external solution was observed at $490 \mathrm{~nm}$. However, the absorption peak at $490 \mathrm{~nm}$ was not observed for the external solution of the PAAc gel particles with DNA. These results indicate that EtBr was immobilized into PAAc gel particles and did not diffuse into the external solution because it was intercalated into the double-stranded structure of the DNA.

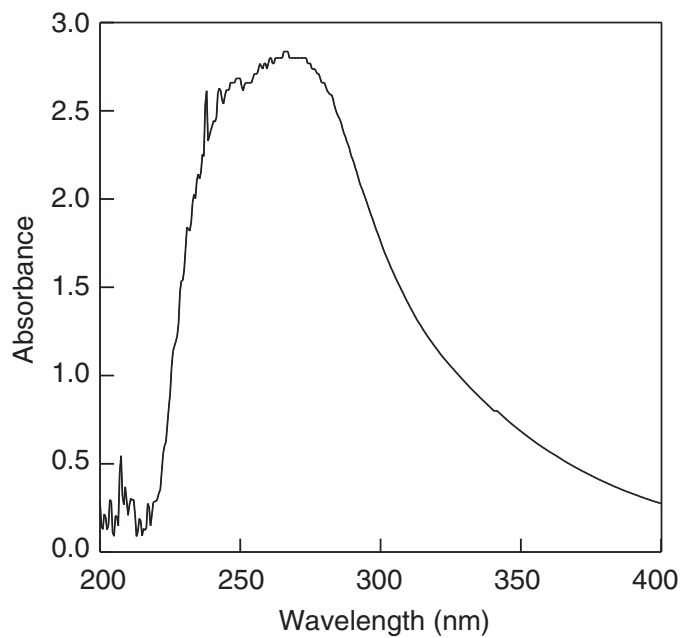

Figure 2 UV-Vis spectrum of PAAc gel particles with DNA, which is a differential spectrum based on PAAc gel particles without DNA.

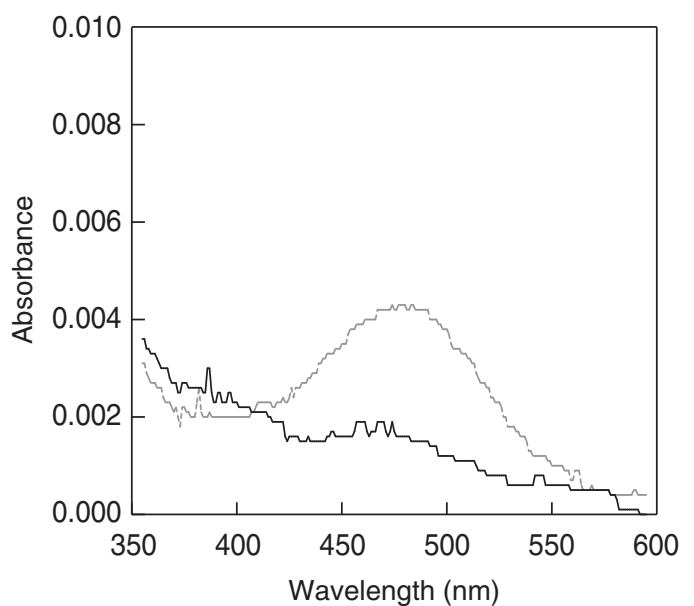

Figure 3 UV-Vis spectra of the buffer solution in which the PAAc gel particles containing $\mathrm{EtBr}$ and PAAc gel particles with DNA-EtBr complexes were immersed. The gray dotted line indicates the UV-Vis spectrum of the solution of PAAc gel particles containing $\mathrm{EtBr}$, and the black line indicates that of PAAc gel particles with DNA-EtBr complexes.
pH-sensitivity of PAAc gel particles with the DNA-EtBr complex PAAc gel is a material that swells and shrinks in response to changes in the $\mathrm{pH}$ of the external environment. Figure 4 shows the swelling ratio of PAAc gel particles with DNA-EtBr complexes in the $\mathrm{pH}$ range from 2-12. The swelling ratio of PAAc gel particles with DNA-EtBr complexes increased with $\mathrm{pH}$ in constant ionic strength buffers. The inset data in Figure 4 show the swelling ratio of PAAc gel particles with DNA-EtBr complexes in the neutral $\mathrm{pH}$ region. The swelling ratio of PAAc gel particles with DNA-EtBr complexes in the neutral $\mathrm{pH}$ region was closely measured. The $\mathrm{pH}$ buffer solutions in the neutral $\mathrm{pH}$ region were finely adjusted for $\mathrm{pH}$ value. Similar to the results shown in Figure 4, the swelling ratio in the neutral $\mathrm{pH}$ region increased linearly with $\mathrm{pH}$.

The effect of ionic strength on the swelling behavior was investigated by using different ionic strength buffers. The ionic strength for the data in Figure 4 and the corresponding inset data was at 0.1 and 1.0 , respectively. The swelling ratio for an ionic strength at 1.0 reflected more swelling behavior than that for an ionic strength at 0.1 . This result suggests that the solvent enhanced the release of ionic solution in terms of osmotic pressure.

Figure 5 shows the time course of the swelling ratio of PAAc gel particles with DNA-EtBr complexes at a $\mathrm{pH}$ of 7.4. In this buffer solution, PAAc gel particles with DNA-EtBr complexes shrunk rapidly, and the volume was constant after $60 \mathrm{~s}$, which implies that equilibrium swelling was reached in about $60 \mathrm{~s}$. A PAAc block gel, which forms in a cylindrical shape and has the same chemical composition as the gel particles, was also synthesized, and the $\mathrm{pH}$ response speeds of the block gel and the gel particles were compared. The PAAc block gel with DNA (with a volume of about $10 \mathrm{~cm}^{3}$ ) reached equilibrium swelling after about $10 \mathrm{~h}$. It was observed that the $\mathrm{pH}$ response speed of PAAc gel particles was about 600 times faster than that of the PAAc block gel. Additionally, the color of PAAc gel particles with DNA-EtBr complexes changed as a function of the volume alteration of the particles. The concentration of dye in the gel particles increased with the shrinkage of the gel particles and decreased with the swelling of the gel particles. This result indicates that $\mathrm{pH}$-sensing could be accomplished by photo analyzing micro-regions with the gel particles.

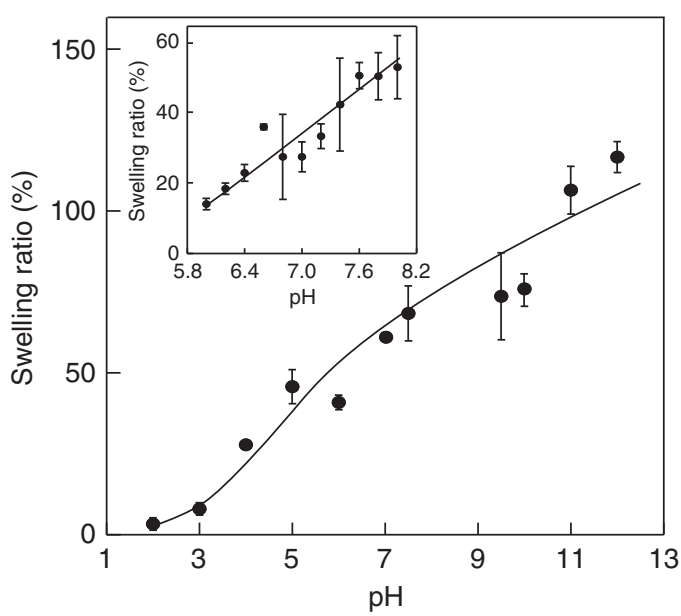

Figure 4 Swelling ratio of PAAc gel particles with DNA-EtBr complexes at constant ionic strength buffer solutions in various $\mathrm{pH}$ (ionic strength is 0.1 ). The inset data show the swelling ratio of the gel particles at constant ionic strength buffer solutions in the neutral $\mathrm{pH}$ region (ionic strength is 1.0). 


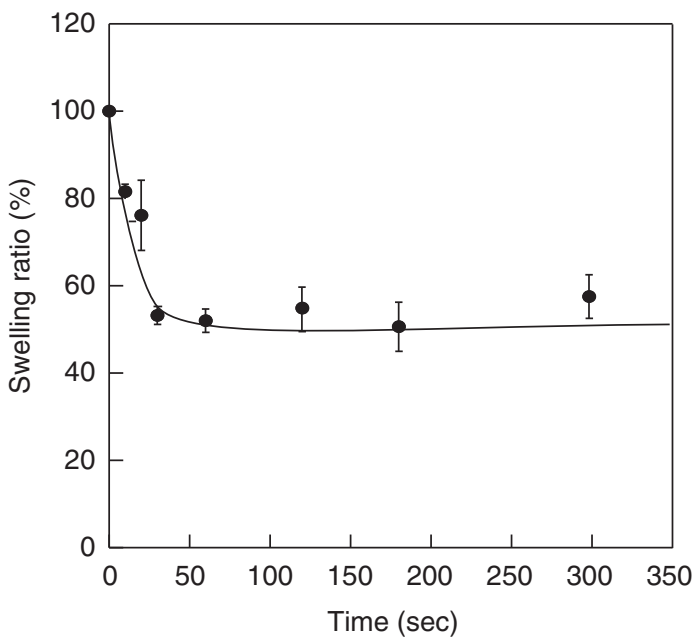

Figure 5 Time course of the swelling ratio of PAAc gel particles with DNA$\mathrm{EtBr}$ complexes in $\mathrm{pH} 7.4$ buffer solution.
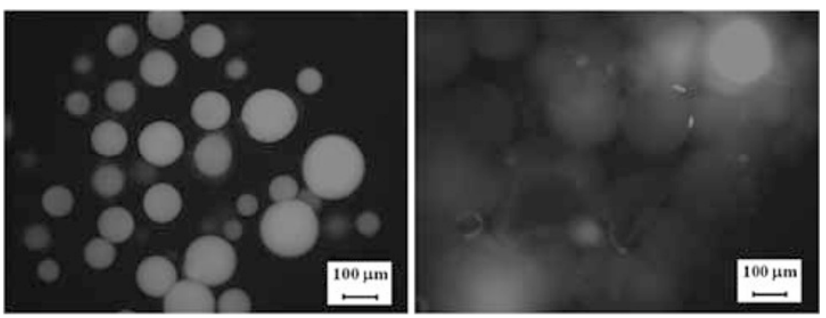

Figure 6 Fluorescence micrographs of PAAc gel particles with DNA-EtBr complexes. The left image indicates the gel particles in $\mathrm{pH} 2.1$ buffer solution and the right indicates that of $\mathrm{pH}$ 11.0.

\section{Fluorescence property of PAAc gel particles with the DNA-EtBr complex}

The fluorescence intensity was measured for one of the PAAc gel particles with DNA-EtBr complexes in buffer solution at $\mathrm{pH}$ values of 2.1, 5.0, 7.4, 9.0, 11.0 and 13.0. The fluorescence intensity was exponentially decreased with increasing $\mathrm{pH}$, and the intensity could be resolved with high-sensitivity. The fluorescence intensity was low at $\mathrm{pH}$ values of 11.0 and 13.0. In the case of $\mathrm{pH} 11.0$, the fluorescence peak was only observed at $625 \mathrm{~nm}$, but no peak was observed at $\mathrm{pH}$ 13.0. Figure 6 shows fluorescence micrographs of PAAc gel particles with DNA-EtBr complexes in buffer solutions at $\mathrm{pH} 2.1$ and 11.0. In the $\mathrm{pH} 2.1$ buffer solution, fluorescence emission was observed to be strong in PAAc gel particles with DNA-EtBr complexes by irradiating with green laser light at a wavelength of $532 \mathrm{~nm}$. Limited fluorescence emission was observed at $\mathrm{pH}$ 11.0.

Figure 7 shows the relationship between fluorescence intensity and the $\mathrm{pH}$ of the PAAc gel particles with DNA-EtBr complexes at wavelength $625 \mathrm{~nm}$. The $\mathrm{pH}$ changes of the gel particles could be detected with high-sensitivity by the fluorescence intensity. The fluorescence intensity was exponentially decreased from $\mathrm{pH} 2.1$ to 9.0. Fluorescence intensity at $\mathrm{pH} 11.0$ and 13.0 was sharply decreased. In $\mathrm{pH} 11.0$ and 13.0 buffer solutions, a small amount of EtBr was eluted from the PAAc gel particles with DNA-EtBr complexes because the double-stranded structure of DNA was unwound by the strong alkalinity. However, almost all of the EtBr was immobilized in

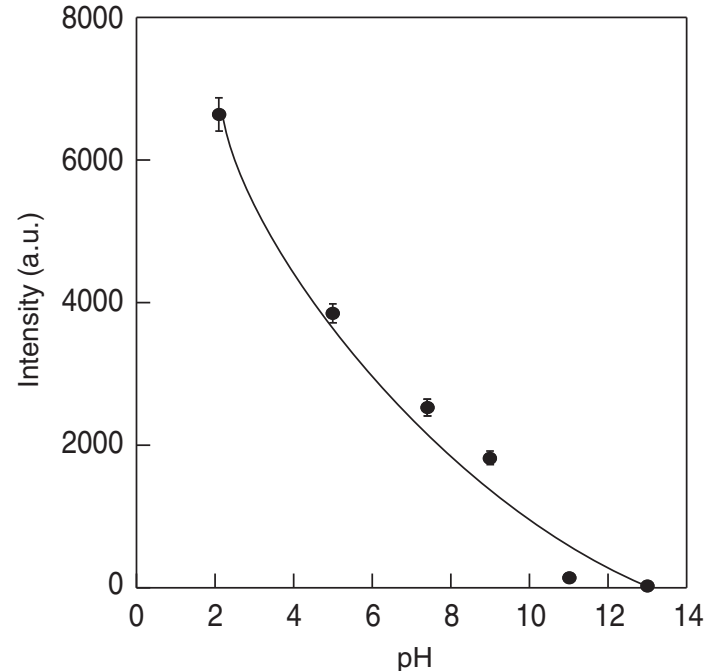

Figure 7 Relationship between $\mathrm{pH}$ and florescence intensity of PAAc gel particles with DNA-EtBr complexes.

the DNA, which was embedded in the gel particles. Therefore, slight fluorescence intensity at $\mathrm{pH}$ value over 11 was observed due to swelling of the gel particles. From these results, it is clear that PAAc gel particles with DNA-EtBr complexes can be used to detect and measure the $\mathrm{pH}$ in the surrounding environment by fluorescence intensity and that this approach could be used to create optical micro$\mathrm{pH}$ sensors.

\section{CONCLUSIONS}

PAAc gel particles with DNA-EtBr complexes were synthesized by emulsion polymerization. DNA was entrapped in PAAc gel particles, and it was not eluted from the gel particles. EtBr was immobilized in PAAc gel particles by intercalating it into the double-stranded structure of DNA, and EtBr did not diffuse into the external solution. The swelling ratio of PAAc gel particles with DNA-EtBr complexes increased with $\mathrm{pH}$. The PAAc gel particles with DNA-EtBr complexes reached equilibrium after $1 \mathrm{~min}$. The $\mathrm{pH}$ response speed of the PAAc gel particles was about 600 times faster than that of a PAAc block gel (with a volume of about $10 \mathrm{~cm}^{3}$ ). The fluorescence intensity of PAAc gel particle with DNA-EtBr complexes provided high-sensitivity and exponentially decreased relative to $\mathrm{pH}$. Consequently, PAAc gel particles with DNA-EtBr complexes could be useful in the development of optical micro-pH sensor devices.

1 Gümüşderelioğlu, M. \& Topal, U. I. Vinyl ether/acrylic acid terpolymer hydrogels synthesized by ãradiation: characterization, thermosensitivity and $\mathrm{pH}$-sensitivity. Radiat. Phys. Chem. 73, 272-279 (2005).

$2 \mathrm{Li}, \mathrm{X}$., Wu, W. \& Liu, W. Synthesis and properties of thermo-responsive guar gum/poly $(N$ isopropylacrylamide) interpenetrating polymer network hydrogels. Carbohydr. Polym. 71, 394-402 (2008)

3 Miyata, T., Asami, N. \& Uragami, T. A reversibly antigen-responsive hydrogel. Nature 399, 766-769 (1999).

4 Miyata, T., Jikihara, A., Nakamae, K. \& Hoffman, A. S. Preparation of reversibly glucose-responsive hydrogels by covalent immobilization of lectin in polymer networks having pendant glucose. J. biomater. Sci. Polym. Edn. 15, 1085-1098 (2004).

5 Miyata, T., Asami, N. \& Uragami, T. Preparation of an Antigen-Sensitive Hydrogel Using AntigenAntibody Bindings. Macromolecules 32, 2082-2084 (1999). 
6 Trinh, T. Q., Gerlach, G., Sorber, J. \& Arndt, K.- F. Hydrogel-based piezoresistive pH sensors: Design, simulation and output characteristics. Sens. Act. B 117, 17-26 (2006).

7 Guenther, M., Gerlach, G., Corten, C., Kuckling, D., Sorber, J. \& Arndt, K.- F. Hydrogelbased sensor for a rheochemical characterization of solutions. Sens. Act. B 132, 471-476 (2008).

8 Kishi, R. \& Osada, Y. Reversible volume change of microparticles in an electric field. J. Chem. Soc., Faraday Trans.1 85, 655-662 (1989).

9 Douthart, J. R. \& Burnet, P. J. Beasley W.F., \& Frank, H.B., Binding of ethidium bromide to double-stranded ribonucleic acid. Biochemistry 12, 214-220 (1973).

10 LePecq, B. J. \& Paoletti, C. A fluorescent complex between ethidium bromide and nucleic acids: Physical—Chemical characterization. J. Mol. Biol. 27, 87-106 (1967).

11 Byrne, D. C. \& de Mello, J. A. Photophysics of ethidium bromide complexed to ct-DNA: a maximum entropy study. Biophys. Chem. 70, 173-184 (1998)

12 Tsuboi, M., Benevides, M. J. \& Thomas Jr, J. G. The Complex of Ethidium Bromide with Genomic DNA: Structure Analysis by Polarized Raman Spectroscopy. Biophys. J. 92, 928-934 (2007).
13 Hendry, L. B., Mahesh, V. B., Bransome, E. D Jr. \& Ewing, D E Small molecule intercalation with double stranded DNA: Implications for normal gene regulation and for predicting the biological efficacy and genotoxicity of drugs and other chemicals. Mutat. Res. 623, 53-71 (2007).

14 Garbett, C. N., Hammond, B. N. \& Graves, E. D. Influence of the amino substituents in the interaction of ethidium bromide with DNA. Biophys. J. 87, 3974-3981 (2004).

15 Ito, Y., Yagi, T., Ohnishi, Y., Kikuchi, K. \& Utikawa, Y. A study on conductive polymer electrodes for stimulating the nervous system,. Int. J. Appl. Electromagn. Mech. 14, 347-352 (2001/2002).

16 Kanda, H., Morimoto, T., Fujikado, T., Tano, Y., Fukuda, Y. \& Sawai1, H. Electrophysiological studies of the feasibility of suprachoroidal-transretinal stimulation for artificial vision in normal and RCS rats. Investig. Ophthalmol. Vis. Sci. 45, 560-566 (2004).

17 Veraart, C., Wanet-Defalque, M.- C., Gérard, B., Vanlierde, A. \& Delbeke, J. Pattern recognition with the optic nerve visual prosthesis. Artif. Organs 27, 996-1004 (2003). 